\title{
Disasters and Humanitarian Crises: A Joint Future for Responders?
}

\author{
Jennifer Leaning, MD, SMH
}

\author{
Harvard Humanitarian Initiative, Harvard \\ School of Public Health, Boston, \\ Massachusetts USA

\section{Correspondence: \\ E-mail: jleaning@hsph.harvard.edu}

Keynote address delivered at the 15th World Congress for Disaster and Emergency Medicine, 14 May 2007, Amsterdam, The Netherlands

Web publication: 27 August 2008
In the last 35 years, the disaster and humanitarian communities have evolved rapidly in two parallel cohorts. The disaster enterprise in the US and Latin America grew up in the 1970s in response to a series of major earthquakes, hurricanes, and forest fires, culminating with the nuclear disaster at Three Mile Island and the formation of the Federal Emergency Management Agency (FEMA) in 1979/80. The Disaster Program at the Pan-American Health Organization also took form in the 1980s.

The humanitarian enterprise can be traced to the Biafran War of 1968/69, where a range of international, non-governmental organizations (NGOs) converged to respond to support a population that was fleeing a civil war and famine. In the years since, drawn to refugees and internally displaced persons in war circumstances as varied as Angola, Afghanistan, and Bosnia, the humanitarian community has expanded in numbers, reach, and budget. The UN Office for the Coordination of Humanitarian Affairs lists $>400$ major NGOs on its rosters and the overall budget for humanitarian response hovers in the annual range of [US]\$7 billion.

\section{Past}

Despite sharing the same span of years, these two enterprises have taken very different paths, in terms of strategic approaches, operational elements, norms, and contextual frameworks. The disaster bureaucracies of the developed world sit within formal state structures and rely on public funds to employ national professionals at the local, state, and federal level to carry out a whole array of planning and preparedness responsibilities. They construct legal and regulatory structures, engage in planning and training prior to anticipated events, and in time of acute need, perform technical tasks, provide training and guidance, and deliver resources to local areas.

A plane crashes in Sioux City, Iowa in 1989 and the local emergency management and medical systems converge to respond, aided by outside ambulance and medical personnel and by the national American Red Cross. Hurricane Andrew cuts a mile-wide swath across Dade County, Florida in 1992, and emergency management responders from throughout the South, as well as National Guard troops, and FEMA officials and several disaster medical assistance teams (DMATs) from across the country arrive, ready to support or take over from depleted local medical assets, arrange temporary shelter for the newly homeless, and provide loans, emergency funds, and logistical support for the extensive task of clean up and reconstruction.

Similar patterns of operation can be found in Europe and parts of Asia, where the disaster enterprise similarly is tightly situated in the public administration of communities and states.

In less developed parts of the world, however, funds to support the development of disaster response systems require investment that cannot be extracted from the meager public coffers. The absence of a system of law, regulation, and insufficient human and operational resources are forced into harsh light with any of the major disasters reported in these past 35 yearsBhopal, Indian railway disasters, Philippine ferry disasters, mine explosions in China, earthquakes, train crashes, and nuclear explosions in the Soviet Union. Despite the occasional aid of outside international disaster responders, these events have imposed terrible hardships on the affected populations. 
The humanitarian community does not reside within the state system. It is a globalized network, and as such, thrives in its standing as the quintessential product of civil society - formed by NGOs, staffed by private citizens and volunteers, headquartered in the major cities of Europe or North America, distant from and outside the societies that often require their aid. The humanitarian NGOs work closely with the designated humanitarian agencies of the $\mathrm{UN}$, as well as with the institutions of the Red Cross movement, but are militantly not coordinated by any governmental or institutional body. Independence, impartiality, neutrality - these are the guiding principles of action.

The life cycle of these agencies relies on securing private donations and government grants and contracts. The outbreak of crisis or war drives deployment of initial project teams and the set up of operations. Even in mature operations involving many agencies, coordination in the field is spotty. It is clear to all, however, what the work is-stabilizing and securing the health and welfare of populations who have fled from or been trapped by war or famine. Where they have been permitted to work for any length of time, the humanitarian community can point to improvements on the margin. These NGOs work in the poorest or most oppressive regions of the world. Their services almost never are sought when crises hit established and wealthy countries.

\section{Future}

From this vantage point, still early in the 21 st century, the future of these two enterprises looks to be very different from their separate pasts. This future looks more joint and ever more urgent.

The world has changed rapidly during these past 35 years, most especially in categories of population growth, climate change, and globalization. These three categories might seem only somewhat related, but from the perspective of disaster and humanitarian responders, they could not be more disruptively and tightly interconnected.

Thirty-five years ago, the world had almost half the population it does now, and $>90 \%$ of the growth that has occurred has taken place in the poorest countries of the world, intensifying human demand for scarce resources like water and land, increasing settlement in marginal and high-risk areas, and spurring rapid and chaotic growth of cities, many of them on continental coasts or inland waterways. Add what are now certain effects of global warming and other related factors, and it appears inescapable that world sea levels will rise from one to three meters over the next 100 years, and wind and water storms will become much more violent and less seasonally predictable. The influence of globalization (used here to mean a global network of ideas, people, and trade) injects elements of speed, complexity, and inter-relatedness in all events and activities. Pandemics can be spawned and spread very rapidly; ideologies can inflame across non-adjacent states; weapons move in all corners of the global marketplace, and people can talk to each other about these issues before the authorities know they are happening.

This century dawned surprisingly tranquil and held as such for less than two years. For the disaster community, the cataclysm of 9-11 appeared to be a turning point, in terms of massively stepped-up requirements for strategic threat assessment and security planning. Then, severe acute respiratory syndrome (SARS) and pandemic flu surfaced as real risks-and the disaster responders organized their priorities along a not very tidy spectrum of terror and epidemic disease. For the humanitarian community, old wars and new ones posed similarly divergent challenges-the struggle to provide relief to people scattered by intra-state wars (Congo, Darfur) and to secure and maintain a relevant humanitarian role in two international conflicts (Afghanistan, Iraq).

These seemed challenges enough, and challenges that on the surface kept the two communities at work, in parallel play.

But in fact, the pivotal and defining events for both communities may well turn out to have been the hurricanes and earthquakes (and associated tsunamis) of 2005. I am speaking here about Hurricane Katrina, August 2005, the Pakistan-Kashmir earthquake, October 2005, and the Asian tsunami, in the last days of December, 2004.

Why these in particular? Hundreds of thousands have died, millions were made homeless, hundreds of thousands had to flee, millions are now bereft, and perhaps-we don't know-millions will never go home again. But these outcomes, as stark and pervasive as they are, even as excessive as they are to our public jaded sensibilities, are not what prompts my saying the year 2005 is a turning point for our collective enterprises.

The chief reason these disasters must stand out in our historical consciousness is that each one of them completely swamped the coping capacities of their presiding nation states. In so doing, each of these disasters, in their own emergency, exploded key shibboleths of the dominant prowess narrative. Hurricane Katrina showed the world that the United States was not united, was not rich, was not competent, and was not caring. The Pakistan-Kashmir earthquake showed the world that Pakistan was not homogenous, was not xenophobic, and could accommodate help. The Asian tsunami gave the world a glimpse of our collective failure, our collective potential, and our collective fate. Against that wave, we are all victim.

In a sign of how implicitly cataclysmic that year really was, in 2005, the world public witnessed humanitarian workers from war and famine turn to provide acute relief to people stranded, lost, and separated in these massive hurricanes, earthquakes, and floods. For the first time, the International Red Cross, International Medical Corps (IMC), Mercy Corps, Cooperative For Assistance And Relief Everywhere (CARE), and Oxfam deployed in the continental US- to the Gulf States struggling in the aftermath of Hurricane Katrina. Pakistan opened its borders and eased visa requirements in order to allow a wide range of Western NGOs into sensitive areas of central Pakistan and Kashmir, where the aid agencies worked alongside the Pakistani army and Islamic charitable organizations. The seven countries affected by the Asian tsunami saw an unprecedented influx of humanitarian agencies to help with a wide range of search, rescue, salvage, identification, and reconstruction issues. 
The insight to be drawn is not simply that outside help was sought because local resources proved inadequate. The disaster response mantra includes the notion of mutual aid; often following earthquakes, there is a call for international search and rescue teams or in technological disasters, a call for specialized burn or casualty capacity. What occurred in 2005 was an appeal to a set of organizations and a cadre of professionals who worked outside and separate from the classic disaster response community. The people who were sought, the humanitarians, were asked in because they had a very different set of skills and a very different approach to populations in need, and dimly, it was discerned by the disaster professionals, although obvious to the humanitarians, that it was these skills and approaches that were required.

What happened in 2005 is a harbinger of things to come. The factors that created the intensity and extent of these disasters and their sweeping population consequences only are accelerating and gaining strength (population growth in high risk zones, climate change, globalization). It is highly likely that there will be an increasing need for some kind of professional response that can be deployed rapidly in austere disaster settings and that can organize a minimum relief operation in politically fluid if not insecure settings. Hence, the humanitarian community and the disaster community will be called upon soon to work together, in situations in which the political and social stakes will be high.

\section{Focus on Forced Migration}

Is there some organizing principle, some shared understanding of mission, that could enhance and accelerate the chances that when these two communities find themselves together again, they will discern a common purpose?

At the heart of these events is the problem of forced migration. People flee in large numbers from war, famine, devastation-and from major disasters. When they flee, they become vulnerable to further attack and further attrition, and when they re-congregate, they are at risk of new crowd diseases, hunger and malnutrition, and new forms of assault and disorientation in alien political, social, and ecological environments.

Flight can mean traversing continents or running across town. Home is the place where, when you have to go there, they have to take you in. But what is it, when home is the place you have to flee?

Central to the human condition is the freedom and possibility of leaving some place, and the freedom and possibility of staying home. Disasters, wars, famine, and epidemic disease remove this freedom and destroy this possibility. In this way, these crises gnaw at what is most basic in our lives.

With regard to a focus on populations and forced migration, these two communities have taken converging paths to a similar place of recognition. In the last 35 years, disaster responders have moved from a focus on rescue of individuals to an understanding that meeting the acute needs of groups and communities, both physical and psychological, is crucial in mounting a successful response effort. At least in the US, much more attention has been paid in recent years to disaster communications, disaster mental health, and community outreach than would have been seen in fire, storm, flood, plane crash, or earthquake responses in the 1970s. When Julia Taft advised her Soviet counterparts in the first weeks of the international response to the Soviet Armenia earthquake of 1988 that it still was too soon to move from rescue efforts to recovery, the Soviet authorities balked. People needed new temporary housing, after six days, there were not likely to be people alive in the rubble, and the debris now needed to be cleared with the heavy equipment that had just arrived. All of these people huddled by fires-they had to be driven off until new homes could be built in the cleaned-up sites.

Julie Taft listened, but she prevailed, and the fear and tension abated among the local Armenian survivors. They still clung to hope and needed to pick away at their collapsed apartment blocks and schools for another few days before they could come to terms with the death that had entered their lives. They needed to stay close to home.

The humanitarian community continues to maintain a focus on the needs of populations, not individuals, but has been shaped enormously to humanize, professionalize, and individualize this approach by a diffusion of consciousness regarding human rights obligations and by demands from recipients and donors that NGOs become more accountable to universal norms and standards, and more responsive to local circumstances and culture. An inescapable barrage of critical experiences occurred in the 1990s, with the Somali famine and war in 1991-1993, the wars in the former Yugoslavia and Kosovo, and the Rwandan genocide and subsequent crises in refugee camps in Eastern Zaire and Tanzania from $1994 \mathrm{on}$. As a consequence, humanitarian discourse, programming, and personnel training are layered with structured attention to the Sphere standards developed by the major NGOs in coordination with the Red Cross movement, the major human rights documents, particularly those relating to women and children, and the applicable provisions of international humanitarian law relating to civilian protection.

Seasoned disaster responders and humanitarian workers were appalled when they witnessed the first few days and months of the botched relief operations in Hurricane Katrina. The hurricane was large, the floods larger, and the evacuation was a debacle. But the abiding calamity was the failure to see that above all, what we faced in Hurricane Katrina was a massive problem of forced migration. That recognition should have swung into gear an entire host of emergency responses, anticipatory contingency plans, and guidelines and constraints on operations.

Both disaster and humanitarian responders have learned what is most important to saving lives, livelihoods, and promoting human security in these dire settings-establishing physical security, identifying vulnerable and resilient groups, providing minimum levels of food, water, shelter, and emergency medical care, and introducing emergency public health (which consists of setting up rudimentary public health assessments, monitoring systems, and surveillance routines). They know that when crises create desperate and trapped people it is essential to display a show of 
security and administrative coherence. They know that diverse groups of people, suddenly thrown together, have acute sensitivities to messages and behaviors around fairness, non-discrimination, and attention to dignity. They have learned years ago that into detection of public health measures are essential early, when thousands of people, many with chronic illnesses, are packed in unsanitary shelters without access to adequate food and water, let alone health care. They know that mass settlements in closed areas (the Superdome, the Convention Center) are likely to make people afraid and sow violence (tents over an open area were suggested but rejected by the New Orleans authorities). They urged that in the rush to evacuate the flooded and dangerous areas that people not be separated from families and moved thousands of miles away to unfamiliar cities and communities.

These lessons were not heeded in Hurricane Katrina, in part because they came from too few voices, arriving far too late.
We can ill afford to do so badly next time. Massive natural disasters as deadly and dreadful as those in 2005 certainly lie ahead, and there always will be war. Perhaps we will face pandemic disease. These major events will force mass movements of people to flee their homes or to remain trapped in areas against their will.

Much in our separate but converging histories has prepared us now to launch common and synergistic responses, provided we hold on to this foundational insight from 2005:

In crises of forced migration, issues of attacbment and loss, grief and alienation, diversity and dignity, and anger and restitution will be as necessary to address as issues of mass vaccination, water and sanitation, and shelter and food.

Our past has taught us this lesson. The future will not let us forget it. 